\title{
ANALYSIS OF VIRTUAL ENVIRONMENT BENEFIT IN E-LEARNING
}

\section{Martin Novák, Jiří Křupka, Pavel Petr}

\section{Abstract}

The analysis of the virtual environment assets towards the e-learning process improvements is mentioned in this article. The virtual environment was created within the solution of the project 'Virtualization' at the Faculty of Economics and Administration, University of Pardubice. The aim of this project was to eliminate the disproportion of free access to licensed software between groups of part-time and full-time students. The research was realized within selected subjects of the study program System Engineering and Informatics. The subjects were connected to the informatics, applied informatics, control and decision making. Student subject results, student feedback based on electronic questionnaire and data from $\log$ file of virtual server usage were compared and analysed. Based on analysis of virtualization possibilities the solution of virtual environment was implemented through Microsoft Terminal Server.

\section{Key Words}

Education, e-learning, remote access, virtual lab, virtual private network
University of Pardubice jiri.krupka@upce.cz

\section{ARTICLE INFO}

Article type

Full research paper

doi: 10.7160/eriesj.2013.060204

Article history

Received: November 29, 2012

Received in revised form: May 16, 2013

Accepted: May 20, 2013

Available on-line: June 30, 2013 


\section{Introduction}

The analysis of the suggested and realized solution 'Virtual Lab' is mentioned in the article. The solution is a part of two projects 'Virtualization' and 'Development of study programmes, didactic methods and innovation of management model in the area of part-time studies' at the University of Pardubice (UPCE). Realization of the solution ran in three phases. During the preparation of this project, we supposed that the new solution will be beneficial for the students, particularly for part-time students and will bring the improvement in better study results. All the above mentioned were evaluated on the basis of real log files of the users (students) and a questionnaire inquiry which covered five fields. The results were generalized according to the comparable group of students in the academic year 2011/2012 and 2010/2011 for the selected subjects. Virtual lab is used most in these subjects due to its syllabus. Virtualization has become a real social phenomenon (Cvek, 2005). In spite of this, the word virtual has become ordinarily used in education, particularly in the field of distance learning (El-Bakry and Mastorakis, 2009) and e-learning (Doulgeri et al, 2006). The mentioned forms of education contribute to the development of an educated society, which is confirmed in European (the i2010 strategy) and national documents.

There are the constructs like virtual learning environment (Zounek, 2009), virtual lab (Casals-Torrens and Bosch-Tous, 2010; Drigas et al, 2005), virtual class (Drigas, Koukianakis and Glentzes, 2005; Květoň, 2005; Michailidis, Margounakis and Politis, 2005) or virtual University (Průcha, 2003) in distance learning. Virtual learning environment (online learning environment) is possible to define as a technology (hardware and software (SW)), which is used for online learning pursued out of the traditional classroom (Mason and Rennie, 2006 quoted in Zounek, 2009; p. 122). In case of virtual labs we meet the constructs such as: iLab (_iLab, 2011), online lab (_onlineLab, 2011), virtual lab (_virtualLab, 2011; _virtualLab, 2011a), web lab (_webLab, 2011), web virtual laboratory (Smutný, Farana and Smutný, 2005) etc.

The primary reason was to make accessible licensed software for part-time students for realization of this project Virtualization at the Faculty of Economics and Administration (FEA).

At FEA are not any dedicated courses to the virtualization. Basic principles of virtualization are discussed during the lessons of Computer Networks (CNs) and Operating Systems. Students will meet practical usage of virtualization in lessons of CNs. Virtual machines are used as complete independent computers for teaching basics about settings of $\mathrm{CNs}$ and network operating systems in this course. These completely independent virtual computers are used at labs computers to avoid any harm or incorrect setting of hosting operating system of lab computer (students of another courses needs to have perfectly working lab computer, not some testing computer with wrong setting of operating system). Oracle VirtualBox are used at student's labs computers for realization of virtual computers. Due to this desktop virtualization every student has full access to its own virtualization environment and virtual computers. Virtual computers are used during the whole semester; therefore students will learn every basic aspects of virtualization.

Within the study programme System Engineering and Informatics (bachelor's and master's degree) at FEA, full-time students process tasks in their seminars in the computer labs. These are assigned in different licensed SW, e.g. MATLAB. Parttime students have the same conditions for gaining the credit, so they process same or similar tasks. Within the part-time studies 
however, number of hours spent in the labs per term (usually 5 hours) cannot be compared to the number of hours spent there by full-time students (usually 28 hours).

The aim of the planned solution was to cancel the disproportion in access to the licensed SW between the full-time and part-time students and of course allow the part-time students full access to the used SW.

\section{Data and Methods}

The research was aimed at the analysis of the virtual environment assets towards the e-learning process via non-stop (24/7) access of the licensed SW to the students.

The research was realized within selected subjects of the study program System Engineering and Informatics for the full-time and distant form of education. The group of subjects was connected to the informatics, applied informatics, control and decision making. We used the methods of analysis and synthesis.

We worked with the hypothesis that 'Accessibility of the licensed SW to the students will improve their skills and academic results'.

Study results of the year 2011 were compared with the data of the year 2010. The questionnaire in the environment of system Moodle was realized to obtain the feedback from the students about the convenience of the suggested solution.

\section{Problem Formulation}

There are many ways, how to allow students the access to the licensed SW, e.g. Figure 1. The left column shows the environment of the University (University), communication channel (Internet) and students' personal computers (Students).
In the picture there are three possibilities of licensed SW distribution for the students. Most of the possible solutions are very complicated and require certain network knowledge for the end users (students). For instance installation of the licensed SW directly to the student's computer is not possible, because the students themselves must also set the school license server after installing the SW. And this activity is not suitable for an ordinary educated computer user.

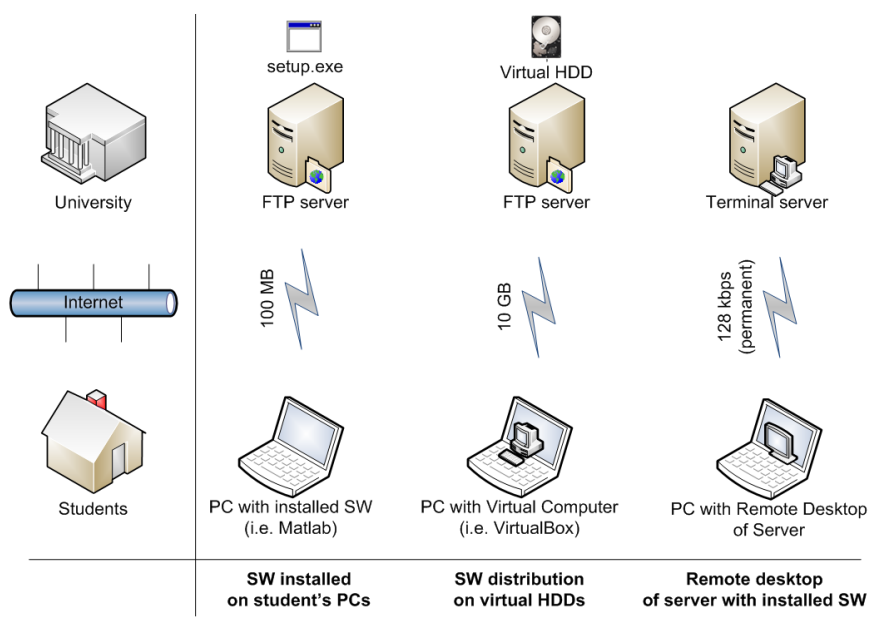

Figure 1: Possibilities of licensed SW distribution

Another possible way is to provide students the installed SW on the virtual computer. Student would only download the image of virtual computer harddrive (Virtual HDD), which would be used for start of the virtual computer in common desktop virtualization environment, such as Windows Virtual PC (it is part of Windows 7), then also Sun VirtualBox or VMware Player (both solutions are accessible free of charge). 
Overall SW and needed settings for getting the licence from the university's licensed server would be the part of distributed virtual computer. Licence to operating system (OS) Windows for students is part of the program Microsoft Developer Network Academic Alliance (MSDN AA). One disadvantage is that there is a necessity to distribute a complete OS Windows, which usually means the usage of 5-10GB of data. Another disadvantage is that there is nearly no possibility to update SW or OS remotely, or to change their settings. Distributed virtual computers would be completely under the end user managing, without the possibility of remote maintenance.

The last mentioned way is our planned solution, via Terminal server.

In the past we solved this problem via allowing licensed SW MATLAB by proposal and analysis of application in MATLAB Web Server (Galčík, 2008). MATLAB Web Server (Galčík, 2008; Hamar, Kropík and Šroubová, 2003) presents the possibility of the Internet communication between MATLAB and the user.

In application (Galčík, 2008) it is necessary: to set Apache HTTP server, to create the input and output forms in HTML code and M-files examples in MATLAB and to prevent making mistakes from the users' (students') side. The advantage is the remote access of the students to the licensed SW. On the other hand the disadvantage is a laborious proposal of HTML forms and M-files for solved examples made by the tutor. Another disadvantage for the students is that there is a possibility to solve the solely defined assignments and their solutions.

\section{Proposal and Solution Testing}

The most advantageous solution for testing was the terminal server at OS Windows Server 2008 R2. At this server there is a necessary SW used in the lessons installed. There are installed MATLAB R2011b and Statistics 10 and a performance of the server is designed to 100 simultaneously working users.

Students have the possibility to connect easily to the remote desktop of the server. At the desktop there are the icons for the program start, which are installed at the server. After the program starts, the student can work on it without any limits as if the program was started directly at their computer.

For connection to this server, there is a simple program needed. It is either part of the student's OS or accessible free of charge. The students can connect from OS Windows (e.g. program Remote Desktop Connection, which is part of OS), from Linux OS (e.g. program rdesktop, which is either part of Linux or accessible to download free of charge) to the remote desktop of the server and it is possible to connect also from Mac OS (e.g. program Remote Desktop for Mac, which is part of the Microsoft Office set for Mac or is accessible to download free of charge). Thanks to the possibility of connection from nearly any desktop OS, the problem with availability of needed SW for lessons, which students use on their computers, is also solved.

After starting the program Remote Desktop Connection for connection to the server, the students only enter the server address (fes-st01.upceucebny.cz). They can also set a connection to any of their disk drives or a printer to this server. At this disk drive the students can save the example assignment or source data. It is also possible to write into this disk drive, which means that the solution would not be stored only at the server. After connection it is necessary to log in to the server, which will be done via student's NetID and the password. The server is accessible for all the students and tutors of FEA at the UPCE. There are no limits yet, e.g. access only for the students of the specific field or time limits, when the application in the server 
would be accessible only during the night or at the weekends. It is possible to access the server at any time from the University's $\mathrm{CN}$. If the student is connected to the Internet out of the University network, the server would be accessible after log in to Virtual Private Network (VPN) of University. The students $\log$ in to the VPN also via their NetID. The client for the VPN connection is also accessible for all three above mentioned OS, i.e. Windows (Windows 2000, Windows XP, Windows Vista, Windows 7), Linux a Mac OS.

Figure 2 shows user's connection from home via VPN to the terminal server from the OS Windows XP via program Remote Desktop Connection. At the virtual desktop there is MATLAB running, where the simple example is shown. The remote desktop window can be widened over the whole screen and provides nearly same comfort as if the students sit at their computers in the classroom.

Naturally to have the access to the remote desktop, within this project, the students' computers must be connected to the Internet. The minimal speed of the Internet connection is $128 \mathrm{kbps}$ for work in the virtual lab. For a comfortable work with the virtual lab the optimal speed of the Internet connection is 512 to $1024 \mathrm{kbps}$. This requirement is accomplished by most of the commercially provided Internet connections in the Czech Republic.

More important factor than the Internet connection speed is actually response time called ping. The response time is the time, when the user gets the response to his request. Nowadays the Internet servers are very powerful and quick, so the most limiting factor is just the quality of the line, which the user connects the Internet with. Considering the work with graphic user's environment of the OS, the interactivity of the environment is necessary (the graphic environment must react quickly to the user's requirements), the response time is a key parameter for the user friendly work with the remote desktop. The suitable response time is therefore 10 to $20 \mathrm{~ms}$, maximum $50 \mathrm{~ms}$, for the problem-free work with the remote desktop. Higher response time will be shown as slower response time of the remote OS to the user's actions. The user then thinks that the remote OS is slow and cannot manage the requests quickly enough; this can be compared to the work on the older and less powerful computers. There are no more serious failures and cut-offs, when there is higher response time, only the comfort of using it is lower.

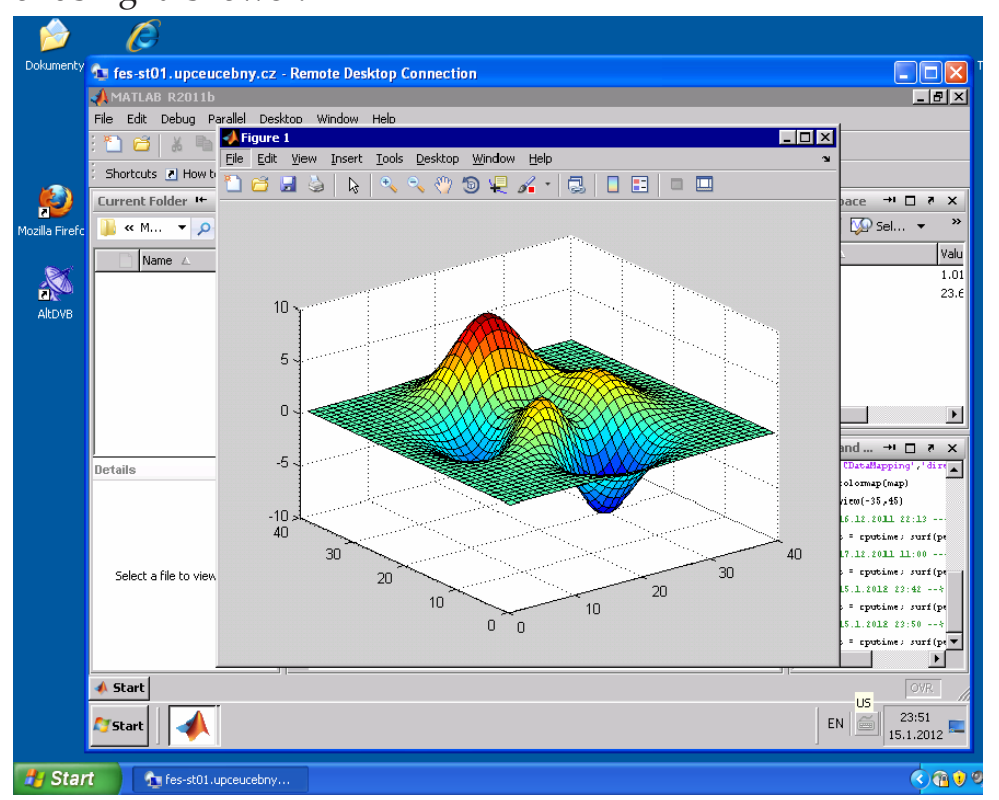

Figure 2: Remote desktop connection to virtual lab in Windows XP 
If the user's (student's) connection to the Internet was lowquality, there would be failures of the connectivity (mainly at the Wi-Fi network in the highly interferenced areas), this problem appears as so called image pixelation (usual at television broadcasting in DVB standard), or by the frozen image. In case of a complete cut-off of the Internet connection, at the first frozen image appears, and then will be the disconnection of the remote desktop. However, at the server there will stay the running programs. If the student logs in to the server soon after the disconnection, the sessions will be recovered and all the programs will stay in the former state. Within the saving of the server resources and licences of the terminal server, the users' (students') disconnected sessions will be automatically closed after some time. This setting has proved to be the compromise between the used licences and server's performance on one side and the user's comfort on the second.

The server itself is run as a virtual computer (Novák, 2012; Novák, Křupka and Petr, 2012) within VMware virtualization environment of the Information Centre (IC) of the UPCE. IC keeps this virtualization environment running, so after the end of this project there will not be any additional operating costs to keeping it running. Virtualization of this server brings many other advantages, such as e.g. very easy back-up of the whole machine, which is possible to be done during its running state. Also very easy transfer of the virtual machine to any other physical server and another advantage is that - in our purpose the most interesting one - its easy change of the virtual machine performance. The change of the performance can be set dynamically, or the change can be done manually. Currently 2 processor cores AMD Opteron 8220 and 48GB of RAM memory are assigned to the virtual server.
Performance and memory of the virtual machine was consulted with experts to MATLAB from the Humusoft and with experienced terminal server administrators. The experiences gained, while testing this solution at the low powerful servers and desktop computers, were also taken into consideration.

There are synthetic laboratory tests, how to test the load of the server, so called stress tests. All these tests are documented in detail and can be repeated, but only in the more or less similar conditions to the real. Due to the fact, that the simulation of the real environment of teaching is very difficult and the data gained by the synthetic tests would not be very relevant, the testing in real environment was proceeded. Testing was done during the lessons, when an example assignment was given to the selected number of students, which was then solved at the tested server. The load of the server really corresponded to the real conditions, for which this server was designed.

The results of the stress test of the server (Processor AMD Opteron 8220) with the licensed SW needed for the lessons at the server are mentioned in the Table 1.

\begin{tabular}{|c|c|c|c|}
\hline CPU Cores & RAM & No. of Users & Result \\
\hline 1 & $16 \mathrm{~GB}$ & 30 & Unusable slow \\
\hline 2 & $48 \mathrm{~GB}$ & 70 & Quick responses \\
\hline
\end{tabular}

Table 1: Results of stress test of the designed virtual lab

Several tests were done with different number of users and different configurations of the server. For instance server with 16GB memory RAM and one assigned core processor AMD Opteron 8220 was already insufficient when 30 users work simultaneously. The most demanding test was done with 70 simultaneously working users in MATLAB and with server 
configuration: 48GB memory RAM and both cores processors AMD Opteron 8220. The server persisted in this test and the work in MATLAB was fluent enough.

We processed the log file after five months of the terminal server operation to find out how the server was used during this period. The log file is a simple text file, which is created only by incremental addition of all events on the server to the end of this $\log$ file. Every event was recorded to the separate line. Log file was pre-processed, i.e. only those records were selected, which were connected to the login and logout of the specific user so that we would be able to say how long this user was logged-in at the server.

The structure of the log file was defined (each value is separated by the semi colon), and therefore it was easy to get the data from the $\log$ file into the prepared database table, as it is obvious from the column 'Table log' in the Figure 3).

Table log
\begin{tabular}{|l|l|}
\hline \multicolumn{1}{|c|}{ Column } & Type \\
\hline date & datetime \\
\hline loginName & tinytext \\
\hline sessionID & tinyint(4) \\
\hline IP & tinytext \\
\hline eventID & tinyint(4) \\
\hline description & tinytext \\
\hline
\end{tabular}

Table log 2
\begin{tabular}{|l|l|}
\hline \multicolumn{1}{|c|}{ Column } & Type \\
\hline ID & int $(10)$ unsigned Auto Increment \\
\hline login & datetime \\
\hline logout & datetime \\
\hline loginName & tinytext \\
\hline sessionID & tinyint(4) \\
\hline IP & tinytext \\
\hline
\end{tabular}

\section{Figure 3: Structure of database tables for log file}

SQL query was used for the copy of all the records about the user's login, which has the event ID number 21 into the 'Table $\log 2^{\prime}$ (in Figure 3):
INSERT INTO $\log 2$ ( $\log$ in, loginName, sessionID, IP) SELECT date, loginName, sessionID, IP FROM log WHERE eventID $=21$;

It was necessary to identify the record for the logout of the user for the records matching, which has event ID number 23 (logout), then the same login name and the same session number, when the time of the logout must not occur earlier than the time of the login. This SQL query was used for records matching:

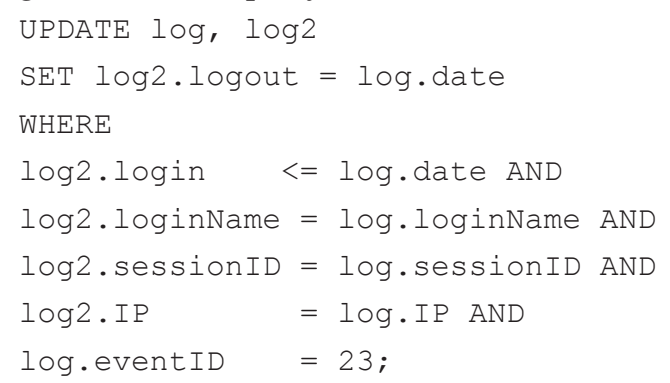

At about $30 \%$ of the records with the login of the user was not found the specific record of the logout. In the log file were not recorded those occurrences, e.g. expiration of the specific relation thanks to the disconnection from the server with a mere closing the window with the remote connection to the server. This problem with the log file was solved after the discussion with the server administrators and since then all the actions, which are connected to the users' access to the server, have been logged.

After the records matching, the data from the database 'Table $\log 2$ ' were exported to Microsoft Excel, where graphs were made from the obtained data (Figure 4 and 5). 


\section{Results}

Placing the server was done in three phases (pilot, testing and operating). In the months of January and February 2012, there was a pilot phase of the server run, especially for the distant form of education. In this phase the students only solved the partial project tasks and among the students an electronic questionnaire inquiry was asked. The partial result is possible to deduce from the respondents' answers, i.e. the accessibility of the licensed SW is a huge advantage and will help with the basic SW skills manage just before the practical form of education at the computer laboratory. However, comparing the academic results the average evaluation was not reached nor at any subjects neither at the frequency of the marks while comparing them with the Gaussian distribution.

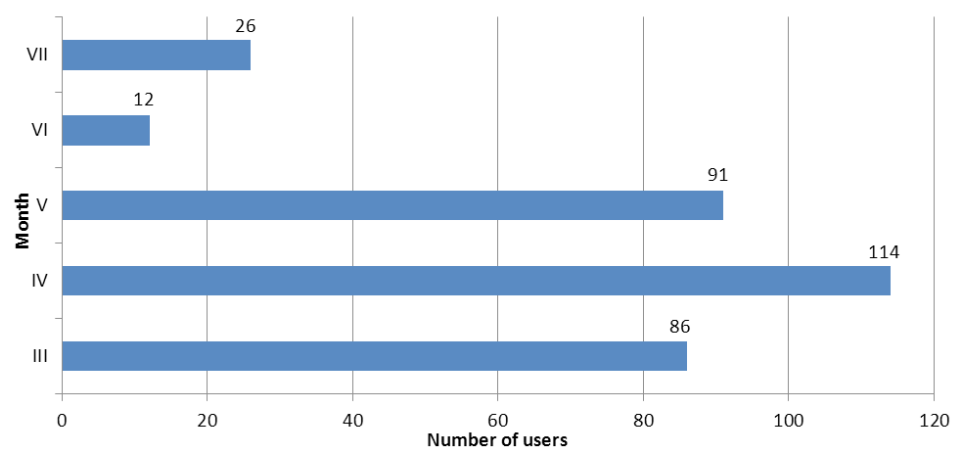

Figure 4: Number of users logged on the server

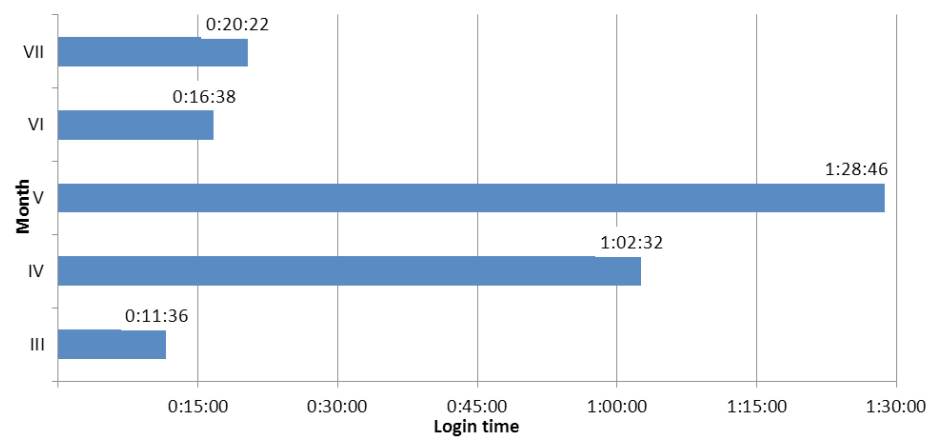

Figure 5: Average login time on the server

The server was tested from March 2012, so the average time of the server login was quite short (Figure 4 and 5). In April and May (the run of the server), on the other hand, the time of the login to the server was much higher. The students of the distant and full-time studies processed the given home projects with the joint denominator - using the SW MATLAB/Simulink. In June and July the server was used only occasionally again.

A questionnaire inquiry was realized in the testing and operating phase. Its aim was to find out the suitability or unsuitability of the suggested 'virtual' solution in the selected group of students. Students compared the virtual lab with the real lab at the university. Questionnaire related to these selected areas:

- Restrictions of work with regard to virtual lab connection

- Intuitive control

- Comfort of work and response time

- Preferred form of training (Virtual lab or Lab at university)

- Sufficiency of study materials for tasks solving 
A different scale was defined for every area. The study group of subject Decision making processes in the summer term of the academic years 2011/2012 was chosen. This group was comparable to the group of students in the academic years 2010/2011. There were 38 students asked in the questionnaire inquiry. Frequency of the students' answers is in the Table 2.

\begin{tabular}{|c|c|c|c|}
\hline Queried Area & \multicolumn{2}{|r|}{ Scale } & $\begin{array}{c}\text { Frequency of } \\
\text { Answers [\%] }\end{array}$ \\
\hline \multirow{4}{*}{$\begin{array}{l}\text { Restrictions of work } \\
\text { with regard to virtual } \\
\text { lab connection }\end{array}$} & No & No restriction & 60.5 \\
\hline & \multirow{3}{*}{ Yes } & Exceptionally & 28.9 \\
\hline & & Occasionally & 7.9 \\
\hline & & Often & 2.6 \\
\hline \multirow{4}{*}{ Intuitive control } & & A (the best) & 5.3 \\
\hline & & $\mathrm{B}$ & 78.9 \\
\hline & & $\mathrm{C}$ & 10.5 \\
\hline & & $\mathrm{D}$ (the worst) & 5.3 \\
\hline \multirow{4}{*}{$\begin{array}{l}\text { Comfort of work and } \\
\text { response time }\end{array}$} & & A (the best) & 21.1 \\
\hline & & B & 28.9 \\
\hline & & $\mathrm{C}$ & 28.9 \\
\hline & & $\mathrm{D}$ (the worst) & 21.1 \\
\hline \multirow{5}{*}{$\begin{array}{l}\text { Preferred form of } \\
\text { training (Virtual lab or } \\
\text { Lab at university) }\end{array}$} & & s for Virtual Lab & 26.3 \\
\hline & Rath & Yes for Virtual Lab & 39.5 \\
\hline & & Do not care & 2.6 \\
\hline & & $\begin{array}{l}\text { her Yes for Lab at } \\
\text { university }\end{array}$ & 10.5 \\
\hline & Yes & r Lab at university & 21.1 \\
\hline \multirow{4}{*}{$\begin{array}{c}\text { Sufficiency of study } \\
\text { materials for tasks } \\
\text { solving }\end{array}$} & & $\mathrm{A}$ (the best) & 21.1 \\
\hline & & B & 44.7 \\
\hline & & $\mathrm{C}$ & 28.9 \\
\hline & & $\mathrm{D}$ (the worst) & 5.3 \\
\hline
\end{tabular}

Table 2: Results of questionnaire

Interpretation of the results for the area 'Restrictions of work with regard to virtual lab connection' is in the Figure 6.

When comparing the study results of the subjects, where the licensed SW was used, the basic improvement of the study average of marks (evaluations) was not reached unfortunately.
There is an example of subject Decision making processes in the summer term of academic years 2011-2012 and 2010-2011 (Figure 7 and 8). There is a change in frequency towards their comparison with the Gaussian distribution, the evaluation (mark) 'very well' occurred more often.

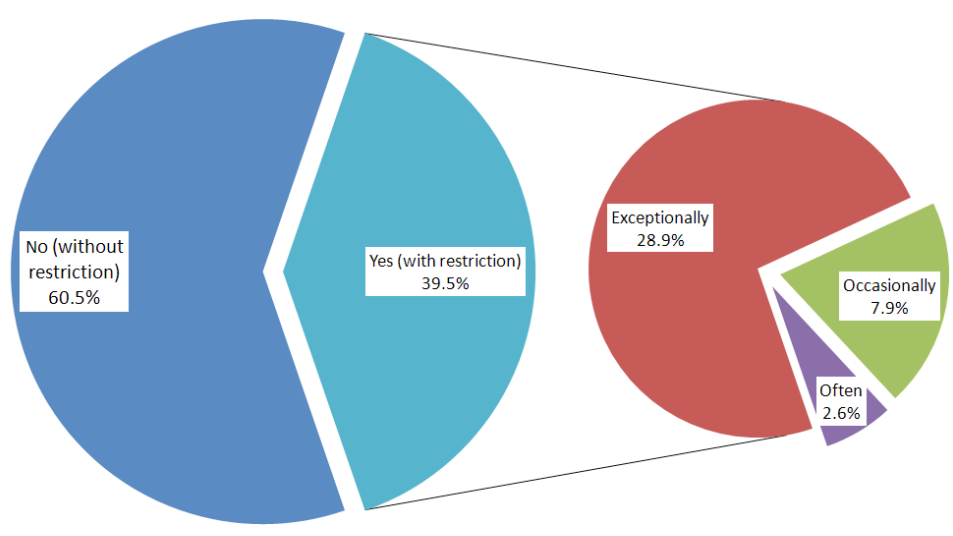

Figure 6: Frequency of the Restrictions of work with regard to virtual lab connection

An electronic questionnaire inquiry was given to selected students group. From the respondents' answers is possible to deduce that:

- The accessibility of the licensed SW is the improvement to the students 


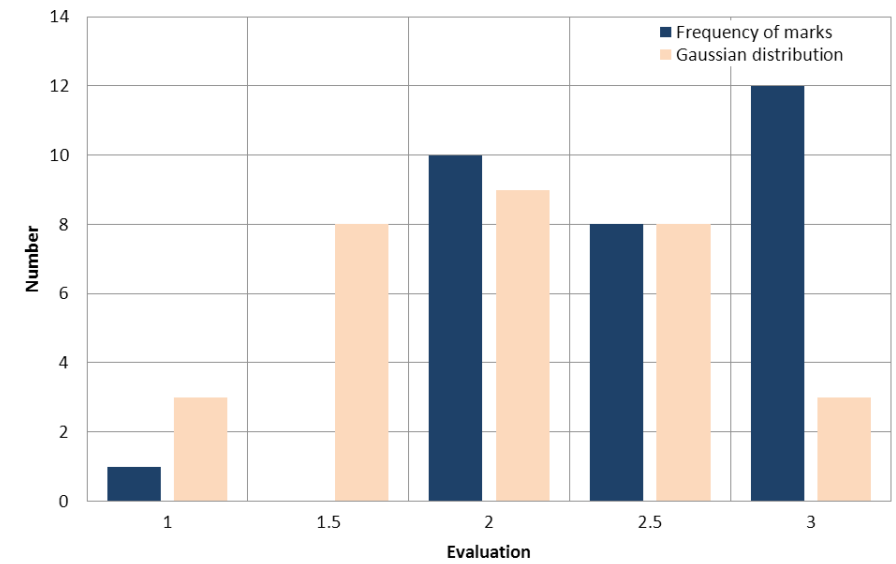

Figure 7: Frequency of the marks in the subject evaluation in 2011

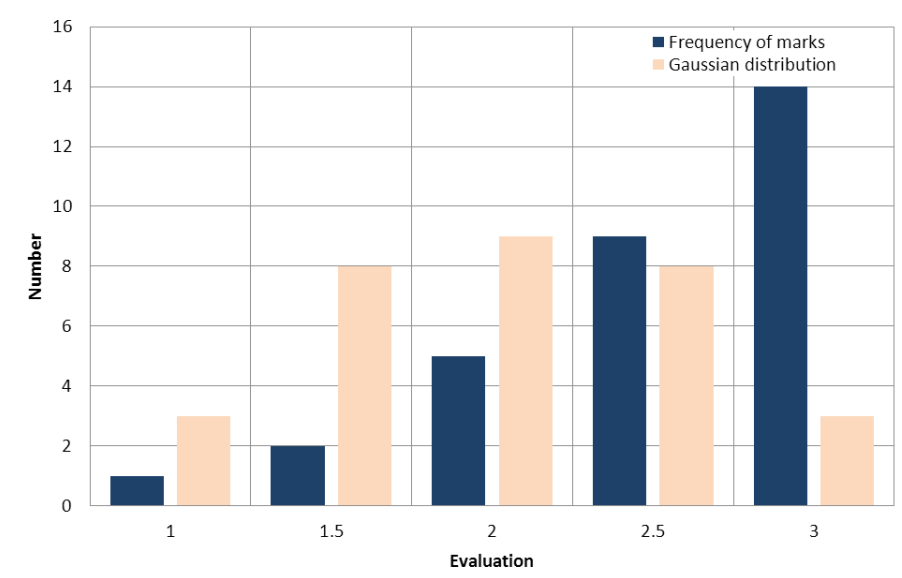

Figure 8: Frequency of the marks in the subject of evaluation in 2010
- The students evaluate positively the possibility of homework correction from the computer tasks from 'home' environment

- SW was used for writing their thesis

From the overall view of the server, the number of users in all three phases was quite low. It is probably caused by the announcement about the server existence only to the small groups of students in the selected subjects. The possibility of using the installed SW from anywhere at the suitable subjects at the beginning of the term will be announced in the following winter term, which means that we expect much higher usage of the terminal server. Thanks to the 'small' amount of students using the SW we have not had to solve the problems with overloading the server yet.

\section{Discussion}

The program ArcGIS was installed (from August to September) after the other development and higher usage of the terminal server in the winter term. This software is used at the subjects like Geographic Information Systems, Space Regional Analysis, Map server services and Basics of the Geographic Information Systems. Thanks to the number of students in these subjects it is likely, that the usage of the terminal server will rise by minimally $100 \%$.

GIS applications are very demanding to the drive space (approximately gigabytes) and therefore it was necessary to make other changes at the terminal server. There was added another drive to the virtual server, which is 50GB big and is seen as drive D: at Windows environment. The size of this drive can be dynamically increased according to the requirements. At this drive D: there is the right for the teachers to write, but 
the students have only the right to read. The data is shared this drive at the moment, at the units of gigabytes for the need of GIS subjects teaching.

Every user has also their own home directory, where they have their own access rights. These home directories are placed at the other drive at the size of 50GB. The users share this drive space. There have not been set any drive quotes for each user yet within the testing run of this solution. Data of the users at this drive also stay there after their logout. It is then possible to leave the unfinished work. From the view of the other development and terminal server run, especially for the reason not to have drive full of users' data, it will be necessary to set the drive quotes or automatic data deleting, which will be older than the set time. Disadvantage of the drive quotes will be inadequate drive space for one student (number of students might be higher). Data deleting can be very easily got around by changing the time of the last access to the file, which means that the suitable solution has not been chosen yet.

Technical solution of the drive space connected to the terminal server is possible thanks to the external disk array, which is connected to the virtual computer via reserved 1Gbps network. Resistance towards the HW failures, power supply and back up of the data is globally solved within the disk array. Speed of the disk operations at the terminal server is comparable or better than the speed of the current hard disks at the common personal computers.

\section{Future development of the terminal server}

It is possible to install other SWs, which are used at FEA, UPCE for teaching, after the successful installation of the ArcGIS program. Scaling of the selected solution (i.e. increase of the operational memory, capacity of the hard drive, performance of the processor) is large and the dynamic changes are possible according to the actual loading of the virtual computer. All the administration work provides IC UPCE, which runs the virtual server within the virtualization infrastructure.

Data in the amount of gigabytes, shared for the students at the drive $\mathrm{D}$, are commonly used also at the teaching the students at full-time studies. The students of the distant studies have the same data and do not have to take gigabytes of the data to their home computer and have also the accessible computer with the installed SW needed for their studies.

Program ArcGIS is very demanding for the system resources (tens of gigabytes of RAM and hard drive space approximately). It is quite demanding for the performance of the computer and mainly the time with these requirements to even practise in the ArcGIS program and do a relatively easy task. If we compare the performance of the computer in the laboratory, performance of the students' computers and our terminal server, the terminal server is the number one in performance (see the Table 3).

\begin{tabular}{|l|c|}
\hline Computer & Time \\
\hline $\begin{array}{l}\text { Terminal server (AMD Opteron } 8220 \text { 2.8GHz, 2 cores, } \\
\text { 48GB RAM) }\end{array}$ & 41 minutes \\
\hline Desktop PC (Intel i3 3.3GHz, 2 cores, 4GB RAM) & 6.5 hours \\
\hline
\end{tabular}

Table 3: Time for merging 3GB data ZABAGED in ArcGIS

Students have very effective work station (terminal server), which performance is incomparable with the common PC. This effective station is shared by the students, so that the actual performance depends on the number of connected users at the specific moment, but generally it is the accessible resource for quick solution of also very demanding tasks.

Speed and accessibility of ArcGIS SW at the terminal server is also appreciated by the teachers with the GIS topics. Teachers 
can easily practise the tasks for the students at the effective device, where they do not have to wait for counting the task and have the result nearly instantly.

\section{Conclusion}

The aim of proposed solution of the virtual laboratory, to make licensed SW needed for the lessons to the students' access, was gained. All the students of the FEA UPCE have now programs MATLAB R2011b, Statistics 10 and ArcGIS accessible at the terminal server. Via logging in to the server the student will get the remote desktop. At this desktop there are icons of each program, which are installed to the server. Having started the required program from the server, the students will get full access to the programs needed for their studies.

There were no problems during testing. The terminal server is in fully operating state now. The students have a description and a simple manual how to connect to the server and how to process the assignments, projects and the sources for their thesis.

SW needed for connecting the terminal server (virtual laboratory) is commonly accessible for OS Windows, Linux and Mac OS and it is free of charge. The students can also set access to their own selected disk drives, where it is possible to store the data and assigned tasks at their computers. Another possibility is leaving the data at the server, at the user profile space (i.e. in Documents folder).

The terminal server is accessible directly from the University's network (direct connection), or anywhere from the Internet (it is necessary to $\log$ in to the University's VPN and then $\log$ in to the server itself).

The speed, performance and capacity of the server are rated sufficiently to the current requirements to the number of users, installed SW and also for the chosen OS including running services in this OS. In case of the lack of performance of the server in the future, upgrade can be made easily thanks to the chosen virtualization technology. Just due to it, the results of the project are permanently sustainable also with the other development.

Improvement of learning, knowledge and practical skills has been evident from results of examinations, too. It is true; it was very short time in this semester (approximately two months) when this software was made accessible to the students. An improvement of 15 to $20 \%$ per subject by tutors has increased and also the better results have been demonstrable.

The response of part-time students has been mainly very positive. They have found main contribution in improvement of learning, saving of time and finance. They had to report to school and to verify theoretical knowledge at practical assignments in computer labs during previous semester. With regard to their workload, it was very complicated and time consuming. However, it was complicated for the tutors because they had to be at their workplace at the weekends, too.

This way of learning is supposed (to give access to other software, except MATLAB, IBM SPSS Statistics and IBM SPSS Modeler) to part-time students in other subjects, too especially in the following time period.

We expect that we will continue to monitor the change of the average marks in the subjects and students' opinions on the benefits of the proposed virtual solutions. 


\section{Acknowledgements}

This paper was supported by the project 'Virtualization' No. 16/2/2011/FES and 'RODIS -Development of study programmes, didactic methods and innovation of management model in the area of part-time studies' No. CZ.1.07/2.2.00/15.0358 at the FEA, UPCE.

\section{References}

Casals-Torrens, P. and Bosch-Tous, R. (2010) 'Virtual Labs for learning Electrical Machines in Marine Engineering', Proceedings of the 3rd International Conference on Maritime and Naval Science and Engineering, (MN'10), Constantza, Romania, pp. 108-112.

Cvek, B. (2005) 'Ivan Havel o literatuře, kultuře a světu kolem nás' [Ivan Havel about literature, culture and the world around us] [online] Available http://www.citarny.cz/ index.php?option $=$ com_content\&view $=$ article $\&$ id $=3763 \% 3 \mathrm{~A}$ ivan-havel-rozhovor\&catid $=94 \% 3$ Arozhovory $\&$ Itemid $=3941$ [16 February 2012] (in Czech).

Doulgeri, Z., Tzortzidou, S., Pavlidou, N. and Hassapis, G. (2006) 'Teaching Engineering Courses By Mixing Lectures with Simulation, Telelab Exercises and Group Work', Proceedings of the 6th WSEAS International Conference on Applied Informatics and Communications, Elounda, Greece, pp. 260-264.

Drigas, A.S., Vrettaros, J., Koukianakis, L.G. and Glentzes, J.G. (2005) 'A Virtual Lab and e-learning system for renewable energy sources', Proceedings of the 1st WSEAS / IASME Int. Conf. on Educational Technologies, Tenerife, Canary Islands, Spain, pp. 149-153.
Drigas, A.S., Koukianakis, L.G. and Glentzes, J.G. (2005) ‘An ODL system and Virtual Class for the electrical engineering sector', Proceedings of the 1st WSEAS / IASME Int. Conf. on Educational Technologies, Tenerife, Canary Islands, Spain, pp. 154-159.

El-Bakry, H.M. and Mastorakis, N. (2009) 'Modular Networks for Active E-learning', Proceedings of the 9th WSEAS International Conference on Applied Informatics and Communications (AIC '09), Moscow, Russia, pp. 373-382.

Galčík, P. (2008) Využití aplikace WebServer pro výuku [WebServer application using for teaching], [Master Thesis, tutor: Křupka, J.], Pardubice: University Pardubice. (in Czech).

Hamar, P., Kropík, P. and Šroubová, L. (2003) 'MATLAB Web Server ve výuce teoretické elektrotechniky' [MATLAB Web Server in teaching of theoretical electrical]. Proceedings of the International Conference Technical Computing Prague 2003, MATLAB 2003, Prague. [online] Available http://dsp.vscht.cz/ konference_matlab/matlab03/hamar.pdf [02 February 2012] (in Czech).

Květoň, K. (2005) Úloha e-learningu na školách [The role of e-learning in schools], Ostrava: Centrum informačních technologií Ostravské univerzity, Ostravská univerzita v Ostravě. (in Czech).

Mason, R. and Rennie, F. (2006) Elearning: the Key Concepts, London: Routledge.

Michailidis, N., Margounakis, D. and Politis, D. (2005) 'Evaluation of E-learning Systems: Experiences in Teaching Human - Computer Interactions', Proceedings of the 9th WSEAS International Conference on Automation and Information (ICAI'08), Bucharest, Romania, pp. 531-536. 
Novák, M. (2012) `Využitílicencovaného SW v rámci distančního studia' [Licensed software usage during part-time study], Sbornik $z$ konference Informatika [Proceedings of the conference Informatica], Luhačovice, Czech Republic, pp. 79-80. (in Czech). Novák, M., Křupka, J. and Petr, P. (2012) 'Approach to Solving of Decrease in Disproportion between Groups of Students', Proceedings of the 9th International Conference on Distance Learning in Applied Informatics, Štúrovo, Slovakia, pp. 233-242.

Průcha, J. (2003) Jak psát učební texty pro distanční studium [How to write textbooks for distance learning], Ostrava: NCDV. (in Czech).

Smutný, L., Farana, R. and Smutný, P. (2005) 'Web Support of University Experimental Education by Means of Real and Virtual Lab Stands', Proceedings of the 5th WSEAS Int. Conf. on Multimedia, Internet and Video Technologies, Corfu, Greece, pp. 1-4.

Zounek, J. (2009) E-learning - jedna z podob učení v moderní společnosti [E-learning - a form of learning in modern society], Brno: MUNI Press. (in Czech).

_iLab, 2011. [online] Available https://wikis.mit.edu/confluence/ display/ILAB2/iLabs [16 February 2012].

_onlineLab, 2011. [online] Available http://www.online-lab.net/ [16 February 2012].

_virtualLab, 2011. [online] Available http://www.vlab.co.in/ [16 February 2012].

_virtualLab, 2011. [online] Available http://sage.virtual-labs. ac.in/home/pub/6/ [16 February 2012].

_webLab, 2011. [online] Available https://www.weblab.deusto. es/web/ [16 February 2012]. 